\title{
What are the emerging features of community health insurance schemes in East Africa?
}

This article was published in the following Dove Press journal:

Risk Management and Healthcare Policy

16 June 2009

Number of times this article has been viewed

\section{Robert Basaza ${ }^{1,3}$ \\ George Pariyo ${ }^{2}$ \\ Bart Criel ${ }^{3}$}

'Ministry of Health Uganda, Kampala, Uganda; ${ }^{2}$ Department of Health Policy, Planning and Management, Makerere University School of Public Health, New Mulago Hospital Complex, Kampala, Uganda; ${ }^{3}$ Institute of Tropical Medicine Nationalestraat I55, B-2000 Antwerp, Belgium
Correspondence: Robert Basaza Senior Health Planner, Ministry of Health Uganda, PO Box 27450, Kampala, Uganda Tel +25677428474

Fax +256 4I4340 354

Email rkbasaza@yahoo.com
Background: The three East African countries of Uganda, Tanzania, and Kenya are characterized by high poverty levels, population growth rates, prevalence of HIV/AIDS, under-funding of the health sector, poor access to quality health care, and small health insurance coverage. Tanzania and Kenya have user-fees whereas Uganda abolished user-fees in public-owned health units.

Objective: To provide comparative description of community health insurance $(\mathrm{CHI})$ schemes in three East African countries of Uganda, Tanzania, and Kenya and thereafter provide a basis for future policy research for development of CHI schemes.

Methods: An analytical grid of 10 distinctive items pertaining to the nature of $\mathrm{CHI}$ schemes was developed so as to have a uniform lens of comparing country situations of CHI.

Results and conclusions: The majority of the schemes have been in existence for a relatively short time of less than 10 years and their number remains small. There is need for further research to identify what is the mix and weight of factors that cause people to refrain from joining schemes. Specific issues that could also be addressed in subsequent studies are whether the current schemes provide financial protection, increase access to quality of care and impact on the equity of health services financing and delivery. On the basis of this knowledge, rational policy decisions can be taken. The governments thereafter could consider an option of playing more roles in advocacy, paying for the poorest, and developing an enabling policy and legal framework.

Keywords: community health insurance, low enrolment, policy and Africa

\section{Introduction}

The study provides an analysis of community health insurance (CHI) schemes in three East African countries and thereafter provides a basis for future policy research for development on CHI schemes. These countries are part of the East African Community and have a population of about 82 million. They are also among the poorest countries in the world. The health systems in the three countries face serious challenges, key among them are: high poverty levels, high population growth rates and alarmingly high prevalence rates of HIV/AIDS coupled with under-funding of the health sector. The 2005 World Development Report estimates for gross national income per capita are US\$530 for Kenya, US\$340 for Tanzania, and US\$280 for Uganda. In addition, the 2005 World Health Report points out that these countries have very high population growth rates per annum of $2.4 \%$ for Kenya, $2.6 \%$ for Tanzania and $2.9 \%$ for Uganda. The same report indicates that the total health expenditure as a percentage of the gross domestic product is very low: $4.3 \%$ for both Kenya and Tanzania and $7.3 \%$ for Uganda. These three countries are spending minimally on health care as a

submit your manuscript $\mid$ www.dovepress.con 
percentage of general government expenditure (Kenya 7.2\% and Uganda $10.7 \%$ whereas Tanzania spends $12.7 \%$ ). This is below the target of allocating at least $15 \%$ of the annual budget to the improvement of the health sector, as set in the Abuja Declaration adopted at the 2004 summit of African leaders. More so, the Commission on Macroeconomics and Health recommended a level of financing between US $\$ 30$ and US\$40 per capita per annum for basic health services in low and middle income countries. The UNAIDS cross country report on the global AIDS epidemic indicates that the 2003 prevalence among $15-49$ years old is $6.7 \%$ in Kenya, $8.8 \%$ in Tanzania, and $4.1 \%$ in Uganda. Worse still, economies have been affected by the decline in world prices for major exports. The rising world prices of pharmaceuticals and equipment have further worsened public financing of health services. Social health insurance coverage remains minimal and only for the formal sector in both Kenya and Tanzania. Social health insurance coverage is $30 \%$ of the entire population in Kenya and 5\% in Tanzania. Uganda is still considering legislation and has advanced plans to introduce a similar scheme. Indeed, private health insurance is also very limited and largely confined to health maintenance organizations and commercial insurance firms and covers less than $1 \%$. The financing gap is thus real. It is in this macroeconomic context that the development of community health insurance is currently taking place. Another important element of the context is the accessibility problem experienced by households in their health care-seeking behavior. In the period immediately following the independence of the East African countries similarly to the majority of African states (1961-1970), free health care was a constitutional right and was supposed to be entirely tax-financed. This became unsustainable and in the 1970's and the 1980 's, user fees were progressively introduced at the time and point of use. Today, the limitations of user fees are well-established: they constitute a barrier to health care and are a cause of exclusion, especially for poor population groups. While Kenya and Tanzania have user fees, Uganda abolished user fees in the general wings of public facilities in 2001. The fees remained in the private wings and private health units. Social health insurance arrangements however, never succeeded in covering the informal sector. It is in this context that private not-for-profit CHI schemes have become an emerging movement in the 1990's. ${ }^{1}$

Community health insurance refers to not-for-profit health insurance schemes developed for the informal sector and created on the basis of an ethic of mutual aid and collective pooling of health risks, in which the members participate in its management. ${ }^{2-4}$ In this study, the focus is on CHI schemes that have community rating of the premium and to varying extents have community participation in conception, implementation, or management. Prepayment schemes that do not rely upon a collective pooling mechanism of funds, for profit schemes and mandatory social health insurance schemes are excluded.

Community health insurance is taken as an improvement in comparison to user fees. The World Health Report 2000 pointed out that in those countries with a small formal sector, one viable way of promoting pooling of financial reserves is at the community level. Additionally, the Commission on Macroeconomics and Health recommended a six-pronged approach to domestic resource mobilization at low-income levels of which one is the development of prepayment mechanisms.

The objective of the study is to provide comparative analyses of CHI schemes in the three East African countries and thereafter provide a basis for future policy research for development on CHI schemes.

\section{Methodology}

This is a retrospective analytical study on CHI schemes in three East African countries based on records from the National Associations of CHI schemes available from 1986 up to June 2006. Additional data was collected from Community Health Financing Association of Eastern Africa (CHEFA). An analytical grid comprising of ten distinctive items pertaining to the nature and performance of CHI was developed so as to have a relatively uniform lens of comparing the current country situations of $\mathrm{CHI}$ in Kenya, Tanzania and Uganda (Table1). These features were identified from the existing frameworks and adopted for CHI schemes in East Africa. The grid was designed on the basis of a cross-cutting analysis of four frameworks regularly referred to in the literature..$^{5-8}$ The frameworks were selected on the basis of their application to sub-Saharan schemes and comprehensive coverage of key features of the schemes.

Other sources of information for the Ugandan and Kenyan schemes are ${ }^{4,8}$ and for the Tanzanian schemes., ${ }^{4,9}$ Additional data was collected during a national workshop on health financing held in Dar es Salaam in May 2005 and regional workshop on CHI in Kampala in September 2005. The data collected was updated and collaborated using information from the National CHI Association offices in each of the three countries. Data validation took place during a regional work shop on health financing modalities in Kenya in July 2007. 
Table I Features for the intercountry analysis of Community Health Insurance (CHI) schemes in East Africa

I. Number of existing functional $\mathrm{CHI}$ schemes (by June 2006)

2. Date of inception of the first scheme

3. Urban/rural focus

4. Key features of the design of $\mathrm{CHI}$ schemes (like groups enrolled, benefit package, co-payments). In this context, a group is a set of people who are registered in the same community, organization or work place (burial society, cooperative, school, etc) or who live in the same village).

5. Type of management

6. Enrolled numbers and coverage

7. Drop out rates of enrolled households

8. Existence of national support associations

9. Role of government

10. Role of external agencies/donors

\section{Results}

The results of the study are summarized in Table 2. Tanzania has the highest number of $\mathrm{CHI}$ schemes and persons covered. Tanzania started on schemes earlier than the two other sister countries. The Ugandan and Kenyan CHI schemes are all rural whereas Tanzania has some schemes in urban areas.

With regard to design, the schemes in all the three countries provide medical benefits, either inpatient or outpatient care only or both. They do not cover transportation or burial expenses. In none of the three countries is there any pooling arrangement between individual schemes nor is there any form of re-insurance. The management of the schemes in Kenya and Tanzania is in the hands of the community. In Uganda, however, the situation is different; all the 13 schemes except one are run by (Mission) hospital management committees in collaboration, to varying degrees, with representatives of community members. None of these hospital-based schemes had established links with first-line facilities. This clearly limits the integration of the schemes in the whole network of the district health systems. One new scheme has been established in first-line health units but does not have links with general hospitals. This situation is different in Kenya and Tanzania where the majority of the schemes are based in first-line health units - be it government, private not-for-profit facilities or private for-profit facilities. They have referral arrangements with neighboring hospitals which may be either public or private. In Kenya and Tanzania, the overall management is done by elected committees from the communities.

The data on the Ugandan schemes indicate that premiums and co-payments met initially $80 \%$ of the health care costs of the enrolees but progressively increased to cover $100 \%$ of the costs. The schemes' deficit was initially met by an external donor, the Department for International Cooperation UK and later by the hospitals themselves. No such information is available for Kenya and Tanzania who have a less elaborate data collection system. All the three countries have national umbrella associations that are registered as nongovernmental organizations. They provide a forum for the sharing of experiences, provide technical support to the schemes and fulfil an advocacy function for the $\mathrm{CHI}$ schemes both at government level and vis-à-vis donors. All the three national associations are affiliated into the "Community Health Financing Association for Eastern Africa."

The schemes in Uganda are characterized by high dropout rate, as high as $10 \%$ of the membership per annum. There was no data on dropout rates for the schemes in Kenya and Tanzania.

In regard to initiation of schemes, the schemes in Uganda were initiated with donor support but today none of them receives deficit funding. In Tanzania, the World Bank, the German and American bilateral cooperation agencies (GTZ and USAID) are supporting the development of CHI schemes. In Kenya, the local communities initiated the schemes and later received technical and financial assistance. The German Church Development Service Evangelischer Entwicklungs Dienst (EED) provides support to the nongovernmental organizations involved in running the schemes.

\section{Discussion}

The major limitation of this study is that it relies on secondly sources of data and does not address outcomes or provide a basis on which schemes can be deemed successful or unsuccessful. However, using exisiting data, the upcoming common characteristics of CHI schemes that have been tested out in the region constitute emerging features. These are urban or rural focus, enrolment based on groups, and both outpatient or inpatient benefit packages. The majority of the schemes have been in existence for a relatively short time of less than 10 years and their number and coverage remains small. The role of government and external agencies/donors is also included. These features could provide a basis for future exploration and comparison of CHI schemes in East Africa with other African regions. Community health insurance schemes in the region are largely supported by nongovernmental organisations. Except for Tanzania, government involvement in other countries has been limited. The support of the government to $\mathrm{CHI}$ may consist of four basic roles: promoter, monitor of $\mathrm{CHI}$ activities so as to adjust their performance, trainer of interested groups wishing to establish $\mathrm{CHI}$ schemes, and last but not least as 
Table 2 Community Health Insurance (CHI) situations in East Africa

\begin{tabular}{|c|c|c|c|}
\hline Feature & Uganda & Kenya & Tanzania \\
\hline $\begin{array}{l}\text { Number of recorded CHI schemes } \\
\text { by end of June } 2006\end{array}$ & 13 & 30 & 77 \\
\hline \multirow{4}{*}{$\begin{array}{l}\text { Date of inception of the first } \\
\text { scheme }\end{array}$} & 1986-1990: no schemes & 1986-1990: no scheme & 1986-1990: one scheme \\
\hline & 1990-1994: no schemes & 1990-1994: one scheme & 1990-1994: no data available \\
\hline & 1995-2000: seven schemes & 1995-2000: three schemes & 1995-2000: no data available \\
\hline & 200I-2006: six schemes & 2000-2006: 26 schemes & 2000-2006: 76 schemes \\
\hline $\begin{array}{l}\text { Enrolment and coverage by the end } \\
\text { of June } 2006\end{array}$ & $\begin{array}{l}31,000 \text { people which is about } \\
2 \% \text { of the population of the } \\
\text { primary catchment area of the } \\
\text { hospitals concerned. }\end{array}$ & $\begin{array}{l}3,000 \text { people which is far less than } \\
1 \% \text { of the catchment population. }\end{array}$ & $\begin{array}{l}\text { I.5 million people which is about } \\
6 \% \text { of the catchment population in } \\
67 \text { out of } 113 \text { districts. }\end{array}$ \\
\hline Urban/Rural & $\begin{array}{l}\text { All are rural-based and located } \\
\text { in southern Uganda. }\end{array}$ & $\begin{array}{l}\text { All are rural-based and largely } \\
\text { located in western Kenya. }\end{array}$ & $\begin{array}{l}37 \text { are rural-based and } 39 \\
\text { are urban-based. Distribu- } \\
\text { tion is countrywide. }\end{array}$ \\
\hline Design & $\begin{array}{l}\text { Groups are the main unit of } \\
\text { enrolment (in most instances } \\
60 \% \text { of the group must enrol). } \\
\text { The package covers both in } \\
\text { patient and out patient care } \\
\text { but excludes ARVs. However, } \\
\text { opportunistic infections are } \\
\text { treated. }\end{array}$ & $\begin{array}{l}\text { Scheme enrolment is based on } \\
\text { household. The benefit package var- } \\
\text { ies from scheme to scheme and may } \\
\text { cover either in patient or out patient } \\
\text { care or both.ARVs are excluded but } \\
\text { opportunistic infections are treated. }\end{array}$ & $\begin{array}{l}\text { Membership is based on both } \\
\text { groups and individuals but with no } \\
60 \% \text { rule. The package covers both } \\
\text { in patient and out patient care but } \\
\text { excludes ARVs. However, opportu- } \\
\text { nistic infections are treated. }\end{array}$ \\
\hline Type of management & $\begin{array}{l}\text { Twelve out of the } 13 \text { schemes } \\
\text { are owned and run by mission } \\
\text { hospitals/health centres. }\end{array}$ & $\begin{array}{l}\text { The schemes are run by community } \\
\text { representatives and initiated within } \\
\text { integrated development activities. }\end{array}$ & $\begin{array}{l}\text { Schemes are run by elected } \\
\text { representatives of the local } \\
\text { government councils and group } \\
\text { representatives. }\end{array}$ \\
\hline Average drop-out rates per annum & $10 \%$ & No data available. & No data available. \\
\hline Existence of a national association & Uganda Community Based & Kenya Community Based Health & Tanzania Network of Community \\
\hline and year of registration & $\begin{array}{l}\text { Health Financing Association. } \\
\text { Registered in } 1999 .\end{array}$ & $\begin{array}{l}\text { Financing Association. Registered in } \\
2003 .\end{array}$ & Health Funds. Registered in 2003. \\
\hline The role of government & $\begin{array}{l}\text { Initiated the majority of the } \\
\text { schemes. It only provides sup- } \\
\text { port for monitoring enrolment } \\
\text { into schemes. }\end{array}$ & $\begin{array}{l}\text { The government does not give any } \\
\text { support to the schemes. }\end{array}$ & $\begin{array}{l}\text { Government is an implementer } \\
\text { and cofinancier of the district } \\
\text { based schemes. No definite role in } \\
\text { nongovernmental schemes. }\end{array}$ \\
\hline $\begin{array}{l}\text { The role of the external agencies/ } \\
\text { donors. }\end{array}$ & $\begin{array}{l}\text { All the schemes in Uganda were } \\
\text { initiated with donor support. }\end{array}$ & $\begin{array}{l}\text { Significant role in setting up the } \\
\text { schemes or funding. }\end{array}$ & $\begin{array}{l}\text { All the schemes were initiated } \\
\text { with donor support and continue } \\
\text { to receive technical assistance. }\end{array}$ \\
\hline
\end{tabular}

Abbreviation: ARVs, antiretrovirals.

co-financier of health insurance operations especially of the premiums that cover insurance for the poorest. ${ }^{10,11}$ Only in Tanzania has the government attempted to meet these roles which may partly explain the large coverage. Where there has been community involvement and time to allow $\mathrm{CHI}$ dynamism to take place, relatively higher $\mathrm{CHI}$ coverage has been achieved. This is the case of the Bwamanda scheme in the Democratic Republic of Congo. ${ }^{12}$ The involvement of donors in initiating, funding, and technical assistance raises doubt on sustainability and ownership of CHI schemes. Perhaps governments or communities will need to play a more significant role in CHI schemes in order to address sustainability.

\section{Country schemes}

A country scheme in each of the three countries is presented to provide insight into individual $\mathrm{CHI}$ schemes.

\section{The Community Health Fund (CHF) of Tanzania}

The Community Health Fund (CHF) was piloted in Igunga district from 1996, and subsequently rolled out to 42 of the 92 councils (46\%). User-fees at health care centers and at the dispensary level are implemented as part of the introduction of the $\mathrm{CHF}$ and vary from district to district. CHF is a voluntary scheme which enables a household to pay when they have funds rather than at the time of illness, with members entitled to access services up to and, in some councils, including the 
district hospital level. Membership premia are decided at the council level, and revenues from premia matched by a grant. The government provides a matching grant to the community's contribution with funds from the World Bank. The World Bank also provides technical assistance in management and coordination of the CHF. Funds are managed by the Council Health Services Board and health care facility committees.

The CHF revenues account for up to $20 \%$ of the value of other charges (nonsalary government funds) in some councils, are included in Council health plans, and are used largely for quality improvements. The $\mathrm{CHF}$ is seen as the way forward for the informal sector, with its emphasis on community involvement in the management of health care services, and its potential role in meeting the costs of those unable to pay through government (central or local) subsidy of membership cards. There are positive experiences of Muheza Council with pro-poor card and the council setting clear criteria for defining "the poor" and responsible for mobilizing funds to ensure those unable to pay are covered. Technical support is provided in some regions to create "CHF plus", with a regional facilitation centre. Additional support to the scheme comes from the Tanzanian Network of Community Health Funds. There is planned expansion of schemes through "TIba kwa KAdi" (TIKA) aiming for $10 \%$ coverage, along similar lines to the rural CHF. In this initiative, the government will introduce the schemes in urban and peri-urban areas. Private for profit providers will play a leading role rather than relying on only government and faith-based care health units as providers.

The UMASIDA and Vibindo society mutual health schemes in Dar es Salaam are alternative models, aimed at extending social protection to the poor and excluded. UMASIDA is the acronym for Umoja wa Matibabu Sekta Isiyo Rasmi Dar es Salaam. Vibindo society is an the umbrella organization of informal sector operators. These schemes focus on informal sector employees, with advantages including more flexible membership options for example possibility of household, group, or individual. There are challenges as to how TIKA would interact with the existing schemes in urban areas, given different, less attractive design and higher price. There is also growing concern that CHF may be expensive to establish, manage, and unsustainable due to the externally funded matching grants and will need external evaluation.

\section{Ishaka scheme in Uganda}

The Ishaka CHI scheme is owned and controlled by the Ishaka Adventist Hospital and is situated about $350 \mathrm{~km}$ west of Kampala. It consists of 15 groups, with a total membership of 950 people out of a population of 50,000 people within the catchment area of the hospital. The premium is an equivalent of US\$2 per family member every three months, and a small copayment of US\$0.5 for outpatient consultations and US\$2.5 for every inpatient admission. In the Ishaka scheme, the Ishaka hospital management consults with the communities and then decides on the premium. The benefit package includes all services provided in both outpatient and inpatient departments at Ishaka hospital and includes drugs and diagnostic tests. Dental and optical care are excluded. The scheme also operates measures against adverse selection, including a waiting period of two weeks. Another measure is a group-based enrolment requirement; $60 \%$ of the group must enroll before the scheme becomes operational. User fees at the hospital are a mixture of flat fees and fee-per-service item. Nonscheme members pay an average of US\$5.00 for a consultation, drugs and diagnostics for an outpatient case, and similarly US\$15.00 for an inpatient case. Plans are underway to separate the scheme from the hospital management so that it is owned and controlled by the community. The scheme receives no subsidies from any other organization.

\section{Ayweyo scheme, Nyando District, Kenya}

The Ayweyo scheme was established in 2001 to promote health status of the community members. It is owned by community members who make a monthly contribution and there is a constitution for the group. The scheme is registered by the Ministry of Social Services. The premium is Ksh $100 /=(1 \mathrm{Kshs}=0.01 \mathrm{US} \$)$ per month and the copayment is $\mathrm{Ksh} 50 /=$. Enrolment is on an individual basis and by end of June 2006, the enrolment was 1,026 people out of a target population of 9,000 people $(11 \%)$. The benefit package includes both out- and inpatient care, treatment at the nearest health facility, health education and prevention. Other services provided include poultry keeping, rice farming, a merry-go-round, and civic education provision for members. The specific exclusions are cancer, diabetes, asthma, and hypertension. Fraud control involves auditing and proper book keeping.

On the basis of these findings, it is possible to establish a basic comparison of $\mathrm{CHI}$ features in East Africa with the older and more widespread movement of CHI especially in West Africa. According to records from La Concertation (a regional grouping for $\mathrm{CHI}$ schemes in West and Central Africa), the boost of CHI in the Western part of the continent has led to fast spreading, with a six-fold overall increase in the period $1997-2003$. Indeed by 2006 , nearly 626 CHI initiatives 
were registered. ${ }^{13}$ This could be explained to some extent by a well established tradition of user fees and a strong community focus. Another difference is in the terminology used. In Francophone Africa, the term Mutual Health Organization (MHO) is used. It is the equivalent of the French term Mutuelle de Sante. Atim (1998) defines a MHO as a "voluntary, nonprofit insurance scheme, formed on the basis of an ethic of mutual aid, solidarity and collective pooling of health risks, in which the members participate effectively in its management and functioning". The definition of an MHO suggests that the element of community participation is much more central in the design and running of $\mathrm{CHI}$ in West and Central Africa. From the analysis of East African CHI schemes presented, most of the schemes are community based except in the Ugandan case where the majority are provider-based. Where the schemes are provider-based, these hospitals are private not-for-profit and faith-based. This type of design has advantages: faith-based hospitals are reputed to provide quality health care and generally enjoy people's trust. ${ }^{7,14}$ In West Africa, the majority of schemes are also communitybased and are managed by local people with external support from donors and/or national support organisations. In Central Africa and the Democratic Republic of Congo in particular, is an intermediate situation with a great variety of models, each one of them tailored to the local context. ${ }^{14}$

Throughout Africa, the coverage of CHI remains small, notwithstanding recent evidence coming from Rwanda indicating that $\mathrm{CHI}$ now covers over $60 \%$ of the population. Indeed, the majority of African CHI schemes only cover a few hundred members with $95 \%$ of the schemes having less than 1,000 members. ${ }^{15}$ The precise reasons for the low enrolment are often context-specific but the most often cited explanations are related to the newness of the health insurance concept, the poor quality of health services, and the problem of ability to pay the premiums. ${ }^{16}$ It is clear that the small size of existing CHI schemes limits their effectiveness and sustainability. A priority area for research would be to investigate in a variety of settings what the main bottlenecks are and how they can be overcome and the evidence of impact that $\mathrm{CHI}$ schemes have on the health system. The three countries present high poverty levels and it could be a challenge for the communities to raise their contributions to the schemes.

A final issue relates to the role of donors and government. In East Africa, donors have played a crucial role in establishing schemes and continue to provide technical assistance to most schemes. Some schemes continue to receive financial assistance from donors and government. This is not different from West Africa. The case of Tanzania is however quite specific; the government of Tanzania has attempted to provide a policy, regulatory, and legal framework including government-financed schemes. The Ugandan government only provides limited support in terms of financing activities aimed at monitoring enrolment into the schemes by the national CHI umbrella network organization. Kenya does not provide any funding to the schemes and there is no specific policy or regulatory framework. In West Africa, some countries have also established policy, legal, and regulatory frameworks (for example Senegal and Mali). However, the majority of the states have not yet done so. ${ }^{12,13}$

\section{Conclusions}

The study provides a comparative analytical description of Community Health Insurance schemes in the three East African countries and points out what could be included in a future policy research agenda for development of $\mathrm{CHI}$ schemes. It provides lessons for countries with similar levels of economic development that are considering development of CHI schemes. Despite over a decade of existence of CHI schemes, none of the three East African countries has reached more than $15 \%$ coverage of the catchment population. In most cases, the coverage has remained stable with some schemes even showing a decline. Community involvement in management remains important in Kenya and Tanzania and less so in Uganda. The role of government remains very important in Tanzania but is limited in Uganda and Kenya. In order for the schemes to scale up, there may be a need for increased participation of the communities in the schemes' undertakings. Specifically, this could be in management of CHI schemes particularly mobilization of potential members.

Tanzania has attempted to investigate the issue of low enrolment ${ }^{9}$ but the Kenyan and Ugandan schemes have never benefited from systematic indepth studies to enlighten practitioners and policy makers. Such an investigation would first address the schemes' performance and propose ways of scaling up $\mathrm{CHI}$ in the given local context. If the policy relevance of $\mathrm{CHI}$ is to be appreciated there is great need for more evidence on the performance of CHI schemes. In theory, CHI constitutes an interesting model for financing health care. It enables pooling of resources and thus shares the burden of health care financing. In addition, it can also constitute, depending on its design, a model of organising and empowering users in their interaction with health care providers. In practice however, the attractiveness of the model to the community remains limited. There is great need for further research to attempt to identify the mix and 
relative weight of factors that causes people to refrain from joining schemes, and to investigate which of these factors are vulnerable within what timeframe. Specific issues that could also be addressed in subsequent studies are whether the current schemes provide financial protection and increase access to quality of care. Most importantly, the impact on the equity of health care service financing and delivery could be included. On the basis of consideration of findings of these envisioned studies, rational policy decisions can be taken. The governments thereafter could consider the option of playing more roles in advocacy, paying for the poorest, and developing an enabling policy and legal framework. In paying for the poor and indigent, the government subsidy could partially or completely meet the premium.

\section{Acknowledgments}

Our appreciation goes to Ministry of Health Uganda, the DGIC Belgium, and Institute of Tropical Medicine in Antwerp, Belgium for their assistance in this research.

\section{Disclosure}

Robert Basaza, Bart Criel, and George Pariyo were responsible for the conception and design of the study, analysis and interpretation of data, drafting the paper, and revising it including approval of the final submitted version. The authors report no conflicts of interest in this work.

\section{References}

1. Wiesmann D, Jutting J. The emerging movement of community based health insurance: experience and lessons learned. Afrika Spectrum. 2000;35:193-210.

2. Criel B. Local health insurance systems in developing countries: a policy research paper. Antwerpen: Institute of Tropical Medicine; 2000.
3. Bennett $\mathrm{S}$. The role of community-based health insurance within the health financing system: a framework for analysis. Health Policy Plan. 2004;19:147-158.

4. Musau SN. Community-Based Health Insurance (CBHI): experiences and lessons learned from East Africa. Bethesda, MA: Partnerships for Health Reform (PHR); 1999. Report No:34.

5. Bennett S, Creese A, Monasch R. Health insurance schemes for people outside formal sector employment. Geneva: ARA Papers; 1998. 16/WHO/ARA/CC/98.1.

6. Hohmann J, Weber A, Herzog C, Criel B. InfoSure; health insurance evaluation methodology and information system. GTZ 2001.

7. Shaw P, Ainsworth M. Financing of health services through user fees and insurance: case studies from sub-Saharan Africa. Washington, DC: The World Bank Discussion Paper; 1995. \#29.

8. Microsave. A Compendium: Health Micro-insurance schemes. Strategies and Tools against Social Exclusion and Poverty; 1999.

9. Chee G, Smith K, Kapinga A. Assessment of the community health fund in Hanang district, Tanzania. Bethesda, MA: Abt Associates; 2002. Report No. 015.

10. Carrin G, Desmet M, Basaza R. Social Health Insurance Development in Low-Income Developing Countries: New Roles for Government and Non-profit Health Insurance Organizations in Africa and Asia. In: Scheil-Adlung X, editor. Building Social Security: The Challenge of Privatization. New Brunswick: Transaction Publishers; 2001. p. $125-153$.

11. Franco M, Mbengue C, Atim C. Social Participation in the Development of Mutual Health Organizations in Senegal. Bethesda, MA: Partnerships for Health Reform (PHR); 2004. Report No. 5.

12. Criel B, Kegels G. A health insurance scheme for hospital care in Bwamanda district, Zaire: lessons and questions after 10 years of functioning. Trop Med Int Health. 1997;2(7):654-672.

13. Ndiaye P, Soors M, Criel B. Editorial: A view from beneath: Community Health Insurance in Africa 2007. Trop Med Int Health. 2007;2(2): $157-161$.

14. Atim C, Diop FP, Ett J, Evrard D, Marcadent P, Massiot N. The contribution of mutual health organizations to financing, delivery, and access to health care in West and Central Africa; summary and case studies in six countries. Bethesda, MA: Abt Associates, Partnerships for Health Reform; 1998. Report No. 19.

15. Schmit J, Mayindo J, and Andreas K. Thresholds for health insurance in Rwanda: who should pay how much? Trop Med Int Health. 2007;11(8):1327-1333.

16. Criel B, Waelkens MP. Declining subscriptions to the Maliando Mutual Health Organisation in Guinea-Conakry (West Africa): what is going wrong? Soc Sci Med. 2003;57:1205-1219.
Risk Management and Healthcare Policy

\section{Publish your work in this journal}

Risk Management and Healthcare Policy is an international, peerreviewed, open access journal focusing on all aspects of public health, policy, and preventative measures to promote good health and improve morbidity and mortality in the population. The journal welcomes submitted papers covering original research, basic science, clinical \& epidemio-

\section{Dovepress}

logical studies, reviews and evaluations, guidelines, expert opinion and commentary, case reports and extended reports. The manuscript management system is completely online and includes a very quick and fair peerreview system, which is all easy to use. Visit http://www.dovepress.com/ testimonials.php to read real quotes from published authors. 